Case Report

\title{
Risk factors of hepatitis C in Pakistan
}

\begin{abstract}
Pakistan is facing an epidemic of hepatitis $\mathrm{C}$ in the country. Almost 10 million people are affected with hepatitis $\mathrm{C}$ in Pakistan. Most of the people are unaware of their health status because the disease is asymptomatic in its initial course. The major causes of disease spread are unsafe blood transfusions, re-use of therapeutic syringes, unsafe medical and surgical practices, shaving at barbers, ear and nose piercing. Pakistan is a middle income country and has limited resources. Therefore, it should more focus on devising and implementing the effective preventive strategies to reduce the disease burden of hepatitis C.
\end{abstract}

Keywords: prevention, hcv, Pakistan, risk factors, prevalence, disease patterns
Volume 7 Issue 6 - 2017

\author{
Hassan Mahmood,' Riffat Raja ${ }^{2}$ \\ 'Pakistan Health Research Council (PHRC), Pakistan \\ ${ }^{2}$ Consultant Radiologist, Islamabad, Pakistan
}

Correspondence: Hassan Mahmood, Medical Officer for Viral Hepatitis, Pakistan Health Research Council (PHRC), Islamabad, Pakistan Independent Consultant, Cooperative Agreement, TEPHINET-CDC, Pakistan, Tel +92-300-54I687I,

Email hassanmahmood@hotmail.com

Received: September 20, 2017 | Published: October 30, 2017

\section{Introduction}

Hepatitis $\mathrm{C}$ virus (HCV) infection is major causes of infectious disease morbidity and mortality globally, most morbidity and mortality is due to sequel of chronic infection such as hepatocellular carcinoma (HCC) and decompensated cirrhosis. ${ }^{1}$ WHO estimates that 170 million people are living with chronic $\mathrm{HCV}$ worldwide., ${ }^{2,3}$ Hepatitis C is estimated to cause 366,000 deaths annually. ${ }^{4}$

Pakistan has one of the world's largest burdens of viral hepatitis. ${ }^{2}$ According to a National Hepatitis Survey, approximately 08 million people are living with $\mathrm{HCV}$ in Pakistan. ${ }^{5}$ Most of the people infected with $\mathrm{HCV}$ are not aware of their infection status resulting in delayed diagnosis and treatment. ${ }^{6}$ Delayed diagnosis can result in sequel such as cirrhosis, decompensated chronic liver disease (DCLD) and HCC, ultimately increasing the disease burden for a poor resource country like Pakistan. ${ }^{6}$

Many studies have been conducted to evaluate risk factors for transmission of HCV. One study conducted in 1994 in Pakistan found that household members who had received four or more injections per year have 9-11 times greater chance of being infected with $\mathrm{HCV}^{7}$ Bari et al. ${ }^{8}$ found that increased use of unsafe injections and receiving shave from barbers are significant risk factors ${ }^{8}$ Shah et al. ${ }^{9}$ found that blood transfusions, surgical procedures, therapeutic injections by quacks, dental procedures, and shaving from barbers were important risk factors for hepatitis C. ${ }^{9}$ Rehman et al. ${ }^{10}$ showed that health care workers (HCW) are at high risk of suffering from hepatitis. ${ }^{10}$ Akhtar S et al. ${ }^{11}$ determined that patients with history of hospitalization or those who have received multiple therapeutic injections are at high risk of getting the disease. ${ }^{11}$

\section{Public health importance}

WHO named HCV as a "viral time bomb" because 170 million people are infected with $\mathrm{HCV}$ infection worldwide. ${ }^{12}$ Out of these, 130 million are chronic carriers of the disease and at risk of developing complications of infection particularly chronic liver disease (CLD), such as chronic hepatitis, liver cirrhosis hepatocellular carcinoma. ${ }^{12}$ $\mathrm{HCV}$ seroprevalence was found to have a range from $1 \%$ to $12 \%$ in South Asia. ${ }^{13,14}$ There are three to four million incident cases annually and $70 \%$ of them are at risk of developing chronic hepatitis. In developed countries, two third of liver transplant and 50-76\% of liver cancers are caused by HCV infection. ${ }^{12}$ According to World Health Statistics 2008, liver cirrhosis was the 18th commonest cause of mortality worldwide and if it remains uncontrolled, by 2030, it will become the 13th commonest cause of mortality. ${ }^{15}$

It is said that about 20 to $30 \%$ patients with chronic $\mathrm{HCV}$ infection will develop cirrhosis over a period of 20 years. Thus the quality of life of these patients is greatly impaired due to the complications caused by cirrhosis like; encephalopathy, ascites, coagulopathy, spontaneous bacterial peritonitis, variceal bleeding and hepatocellular carcinoma (HCC). Some of HCV related mortality statistics by worldwide region are as follows (Table 1). ${ }^{15}$

\section{Global prevalence of HCV infection}

Prevalence of $\mathrm{HCV}$ varies in different parts of the world because of different medical, social, cultural, political and behavioural practices. Following Table 2 shows HCV prevalence submitted to WHO by different countries. ${ }^{16}$

Table I HCV related mortality statistics worldwide

\begin{tabular}{ll}
\hline Region & No. of HCV related deaths in $\mathbf{2 0 0 2}$ \\
\hline Africa & 8,000 \\
America & 7,000 \\
South East Asia & 14,000 \\
Europe & 4,000 \\
Eastern Mediterranean & 5,000 \\
Western Pacific & 14,000 \\
\hline
\end{tabular}

\section{Incidence of HCV}

Incidence rate of $\mathrm{HCV}$ fluctuates greatly owing to the asymptomatic and latent course of infection. ${ }^{17}$ Much less data are available about the incidence of $\mathrm{HCV}$ infection because of silent nature of the disease. ${ }^{17}$ A difficulty in establishing the incidence of $\mathrm{HCV}$ infection leads to difficulties in monitoring the effectiveness of primary preventive measures since prevalence data are not enough for this. However, the reported incidence rate for HCV seroconversion is 11-29/100 persons/ year. ${ }^{18}$ Seroconversion is termed as the development of detectable specific antibodies to microorganisms in the blood serum as a result of infection. HCV is found in the blood at low levels and routine serological tests are not very reliable to detect the disease. ${ }^{19}$ Therefore, more sensitive and specific tests like polymerase chain reaction (PCR) and enzyme linked immunosorbent assay (ELISA) are required to confirm the diagnosis. ${ }^{19}$ 
Table 2 Global prevalence of HCV

\begin{tabular}{llll}
\hline Region & Total population (Millions) & Infected population (Millions) & Prevalence (\%) \\
\hline Africa & 602 & 31.9 & 5.3 \\
America & 785 & 13.1 & 1.7 \\
Eastern Mediterranean & 466 & 21.3 & 4.6 \\
Europe & 858 & 8.9 & 1.03 \\
South-East Asia & 1500 & 32.3 & 2.15 \\
Western Pacific & 1600 & 62.2 & 3.9 \\
Total & $\mathbf{5 8 I I}$ & $\mathbf{1 6 9 . 7}$ & $\mathbf{1 8 . 7}$ \\
\hline
\end{tabular}

\section{Demographic features of Pakistan}

Pakistan has a population of 173 million people with the highest fertility rate of more than four children per woman. ${ }^{2,20}$ It is a developing country with population of low socioeconomic status and poor education. According to human development index of the United Nations, it was ranked 134th out of 174 countries. ${ }^{20}$ It covers an area of 796,096 sq. Kilo-metres and is divided into four provinces (Figure 1); Punjab, Sindh, Khyberpakhtunkhwa (Previously known as NWFP), and Balochistan as well as federally administered areas including the capital (Islamabad). ${ }^{2}$

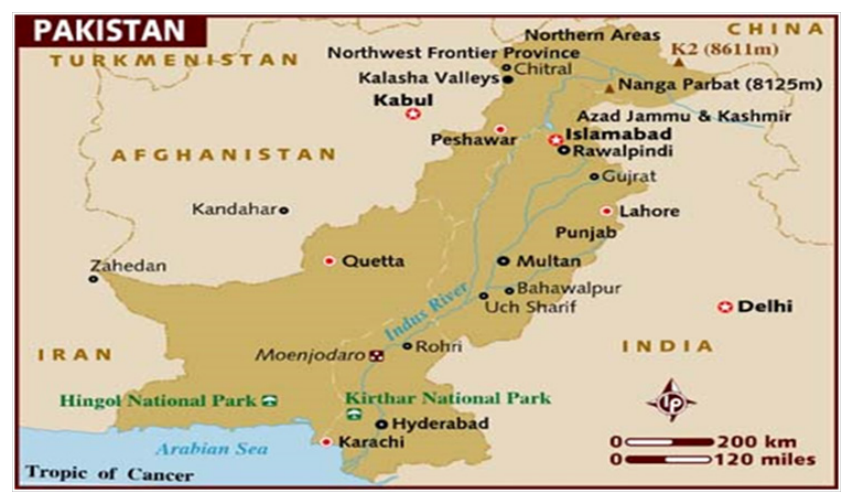

Figure I Map of Pakistan.

\section{Current situation in Pakistan}

$\mathrm{HCV}$ infection is endemic in different parts of the world. ${ }^{5}$ However, prevalence and incidence of HCV considerably changes with geographic and temporal variation. ${ }^{2}$. Although $\mathrm{HCV}$ is becoming a major threat to public health, yet there is very limited information about prevalence and incidence of HCV in Pakistan as compared to most of the developed countries (e.g.UK and USA) of the world where there is enough information about the prevalence and incidence. ${ }^{22}$ However, attempts have been made to measure seroprevalence of $\mathrm{HCV}$ in Pakistan for example; it is found that frequency of $\mathrm{HCV}$ infection ranges from $0.4 \%$ in Karachi (Sindh) to $33.7 \%$ in Jarwar. The mean frequency is $4.7 \%$ with $95 \%$ confidence interval (CI) 4.6 - 4.8. ${ }^{12}$ It is more common among males. In males it mostly occurs between 40-49 years of age while in females between 50-59 years of age.

Different studies show that therapeutic use of contaminated needles in medical care, unsafe blood transfusion; intravenous drug abuse, non sterile surgical and dental procedures are major factors responsible for transmission of $\mathrm{HCV}^{23}$ Prevalence of $\mathrm{HCV}$ varies in the four provinces of Pakistan being highest in Punjab. According to a recent survey conducted by Pakistan medical and research council, the prevalence of HCV in four provinces of Pakistan is as follows; $;{ }^{1,24}$

a) Punjab $6.7 \%$

b) Sindh $5 \%$

c) Balochistan $1.5 \%$

d) Khyberpakhtunkhwa (Previously known as NWFP) 1.1\%

e) Why is it a major public health problem in Pakistan?

More than 10 million people are infected with HCV in Pakistan. ${ }^{25}$ Data suggest that $60-70 \%$ patients who present with chronic liver disease (CLD) are anti HCV positive. ${ }^{26}$ Nearly $50 \%$ patients with liver cell carcinoma or hepatocellular carcinoma (HCC) are anti HCV positive. $^{27}$

Major factors responsible for this high disease burden in Pakistan are;

i. Unnecessary prescription and use of therapeutic injections. ${ }^{12}$

ii. Lack of screening of blood and blood products. ${ }^{28}$.

iii. Reuse of syringes. ${ }^{23}$.

iv. Injecting drug users (IDUs). ${ }^{29}$

v. Unsafe practices by dentists and barbers. ${ }^{29}$

vi. Inadequate regulation against hakeems (traditional healers) and quacks. $^{30}$

vii. Lack of operational research including monitoring evaluation and follow up. ${ }^{31}$

viii. Underreporting of infected cases. ${ }^{32}$

ix. Lack of organization and fragmented health services. ${ }^{33}$

x. Lack of education and risk awareness. ${ }^{34}$

xi. Corruption. ${ }^{33}$

xii. Negligence of higher authorities. ${ }^{35}$

xiii. Natural disasters for example floods and earthquakes. ${ }^{36}$

In developed countries, more concerns and efforts have been made to control the transmission of $\mathrm{HCV}$ infection. As a result the incidence and prevalence of $\mathrm{HCV}$ infections has decreased for example prevalence of $\mathrm{HCV}$ infection in England is $0.4 \% \cdot{ }^{37}$ But it still remains a big problem in developing countries like Pakistan because of factors mentioned above. 


\section{Common risk factors for $\mathrm{HCV}$ transmission in Pakistan}

Risk factors for HCV transmission in Pakistan are different as compared to the developed world. ${ }^{38}$ In developed countries, IDUs are recognised as major risk factor for transmission of HCV infection. ${ }^{39}$ Murphy et al. ${ }^{39}$ conducted a study in USA and found IDUs as a major risk factor for $\mathrm{HCV}$ transmission with a seroprevalence of $51 \%$. Other important risk factors were blood transfusions (17\%), no known risk factor $(10 \%)$, body piercing $(9 \%)$, sex with IDUs $(6 \%)$, prisons $(3 \%)$, needle stick injuries $(2 \%)$ and immunoglobulin treatment $(1 \%)$ as shown in Figure 2. ${ }^{39}$

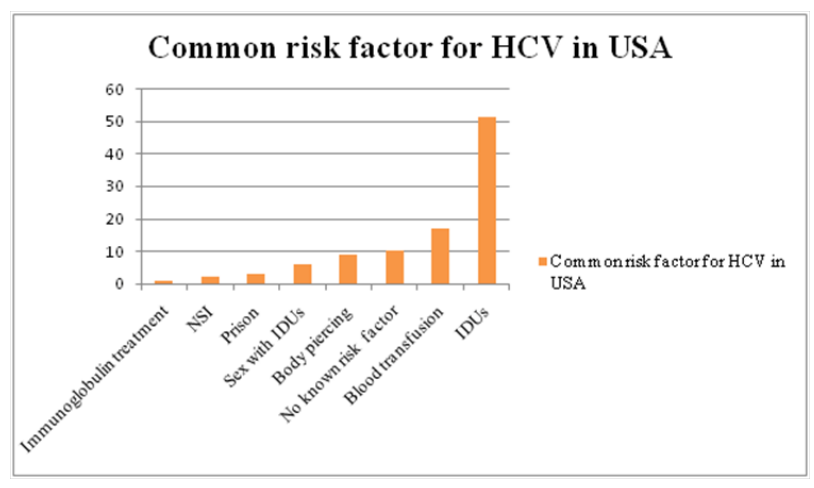

Figure 2 Prevalence (\%) of HCV in USA as per risk factors showing risk factors on horizontal axis and percentage of prevalence of $\mathrm{HCV}$ on vertical axis.

But this is not the case in Pakistan. Several studies have shown that multiple and unnecessary use of injections, unsafe medical/ surgical procedures, use of contaminated razors by barbers, ear, nose piercing, blood transfusions and needle stick injuries (NSI) are major risk factors for HCV infection in Pakistan.29 Following Figure 3 shows the prevalence of $\mathrm{HCV}$ infection in Pakistan due to different risk factors ranging from $27 \%$ because of multiple use of needles to $2 \%$ due to needle stick injuries. ${ }^{29}$

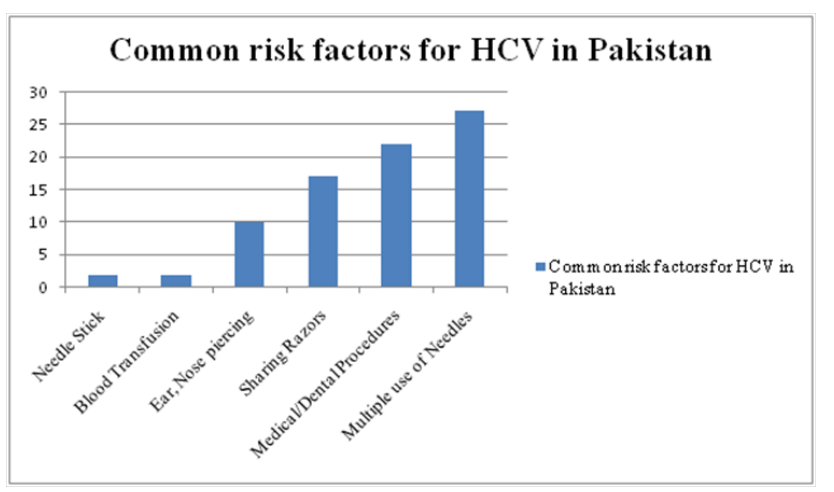

Figure 3 Prevalence (\%) of HCV in Pakistan as per risk factors, showing risk factors on horizontal axis and percentage of prevalence of HCV on vertical axis.

a) Unnecessary therapeutic injections: Pakistan was reported as one of the countries with the highest frequency of injection use in the world with an average of more than 9 injections per person annually. ${ }^{23,34}$ Furthermore, it has been reported that almost 50\% of the patients receive unnecessary therapeutic injections without any safe medical practices including reuse of syringes. ${ }^{40}$ Another survey, published by Ministry of Health Pakistan, mentions that $72 \%$ of the therapeutic injection and $50 \%$ of immunization injections used in the public health care are unsafe and a major risk factor for transmission of HCV infection. ${ }^{40}$ Use of multiple dose vials and recycled syringe is very common in both government and private health sectors of Pakistan contributing a major role in the transmission of $\mathrm{HCV}$ infection. ${ }^{41}$

Reuse of syringes for therapeutic purposes was found to be the most significant factor associated with the transmission of $\mathrm{HCV}$ infection..$^{42}$ A large number of patients, almost $26 \%$ got the infection because they were administered intravenous injections from the GP clinics, which were recognized for reusing the syringes. ${ }^{29}$ People who got the injections were more likely to get HCV infection as compared to those who did not get the injections as shown in Table $3 .{ }^{43}$ Also, household members who received more than four injections per year were 11.9 times more likely to be infected than others with a $p$ value of $0.02 .^{7}$

b) Unsafe medical and surgical practices: Another common factor strongly associated with $\mathrm{HCV}$ infection is unsafe practices during major or minor surgeries and dental procedures. These unsafe practices are recognised as major threat to the health of both the health care providers and patients. Seroprevalence of HCV infection was found to be $5.5 \%$ in health care workers. ${ }^{2}$ These practices include unsafe operating procedures, dental procedures and use of unsterilized instruments in operation theatres, outpatient departments (OPD), medical and surgical wards and emergency departments of hospitals. ${ }^{44}$

Several studies show that factors responsible for unsafe medical and surgical practices are: poor knowledge, ${ }^{45}$ poor skills,${ }^{46}$ lack of riskawareness, ${ }^{47}$ variance of interests, ${ }^{45}$ not wanting to offend patients, ${ }^{48}$ lack of equipment. ${ }^{49}$ and time, uncomfortable personal protective equipment, inconvenience, work stress and perceiving a weak organizational commitment to safety climate. ${ }^{45,46,49}$

In Pakistan, poor qualifications, lack of training, lack of knowledge, absence of a system for prevention of blood borne pathogens and post exposure prophylaxis at health care facilities are the most common factors responsible for increased transmission of $\mathrm{HCV}$ infection. ${ }^{31}$

c) Sharing of razors by barbers: Daily shaves from barbers was found to be significantly associated with $\mathrm{HCV}$ infection. ${ }^{50,51}$ In Pakistan, most of the barbers especially in rural areas are unaware of the risk factors of blood borne infections; hence, they do not sterilize their instruments. Most men aged 20 years and above go to barber shops for shave. The higher incidence of HCV in males than females can be due to contact with unsterilized and used razors. ${ }^{29}$

d) Blood transfusions: Due to screening of blood donors and by performing the tests for HCV surrogate markers, the risk of $\mathrm{HCV}$ transmission has decreased to $0.001 \%$ in developed countries. However, in Pakistan, risk of HCV is unknown but it is considered to be high due to lack of proper screening of blood donors and blood transfusion products. ${ }^{52-54}$ In Pakistan, the mean frequency of $\mathrm{HCV}$ infection among blood donors was found to be $3.0 \%(95 \%$ CI: $3.0-3.1){ }^{12}$

e) Needle Stick Injuries (NSI): Needle stick injuries (NSI) are potential risk factor for HCV transmission in Pakistan. Mostly NSI occur during injecting or drawing of blood, surgeries and suturing, recapping and handling uncooperative patients as shown in the following Figure $4 .^{32}$

f) Injecting Drug Users (IDUs): According to the year 2000 National Assessment Study of Drug Use in Pakistan supported by 
the United Nations Office of Drug Control and Crime Prevention (UNODC), it was found that there were 500,000 heroin addicts in Pakistan, of whom $75,000(15 \%)$ were regular IDUs and $150,000(30 \%)$ were occasional IDUs. ${ }^{55}$ It was revealed that seroprevalence of $\mathrm{HCV}$ was higher (89\%) in IDUs (as compared to general population $(6.5 \%){ }^{56}$

g) Perinatal transmission of $\mathrm{HCV}$ infection: Perinatal transmission of $\mathrm{HCV}$ infection from $\mathrm{HCV}$ positive mother to new born babies is recognised as a major risk factor. Khan et al. ${ }^{57}$ reported a $4.1 \%$ perinatal transmission of $\mathrm{HCV}$ in children of HCV- positive mothers in Lahore, Pakistan. ${ }^{57}$ Previous history of blood transfusions, surgery and gynaecological procedures are most significant risk factors for $\mathrm{HCV}$ infection in pregnant women. ${ }^{58,59}$

h) Other Risk Factors: Other less common risk factors include ear, nose piercing and sexual contact. ${ }^{12,29,60}$ These factors are also recognised to be responsible for $\mathrm{HCV}$ transmission but they are not as common as the other risk factors mentioned above.

i) High risk population: People at risk of developing chronic $\mathrm{HCV}$ infection are;

a) People who had blood transfusion

b) People who had history of surgical, medical or dental procedures

c) Health care workers, doctors and nurses exposed to HCV positive blood after sharps or needle stick injury

d) Diagnosed cases of chronic liver disease

e) Intravenous drug users

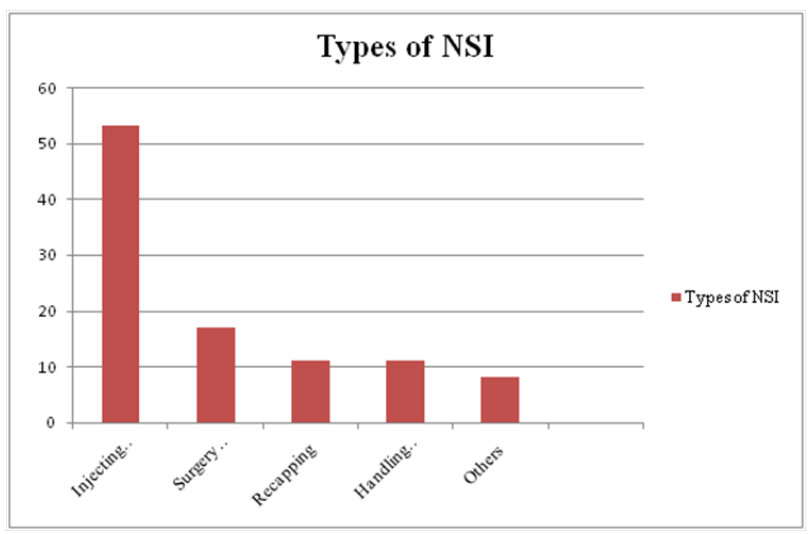

Figure 4 Sharp injuries by injury circumstances in percentage.

Table 3 Relationship between therapeutic injections and HCV infection

\begin{tabular}{llll}
$\begin{array}{l}\text { Average no. of } \\
\text { injections annually in } \\
\text { last I0 years }\end{array}$ & $\begin{array}{l}\mathrm{HCV} \\
\text { positive }\end{array}$ & $\begin{array}{l}\mathrm{HCV} \\
\text { negative }\end{array}$ & $\begin{array}{l}\text { Odds } \\
\text { ratio }\end{array}$ \\
\hline 1 & 0 & 8 & 0 \\
$02-4$ & 2 & 13 & 1.54 \\
$05-9$ & 2 & 8 & 2.5 \\
$>10$ & 9 & 13 & 6.92 \\
\hline
\end{tabular}

\section{Natural history of the disease}

Natural history of $\mathrm{HCV}$ is not completely understood as the disease may take different courses among infected individuals. ${ }^{60} \mathrm{HCV}$ can lead to;

a) Asymptomatic acute infection

b) Persistent infection following acute infection

c) Persistently elevated or fluctuating ALT levels

d) Generally slow but variable disease progression

The appearance of anti HCV antibody may take 5 to 12 weeks after exposure but HCV RNA can be detected as early as 1 to 2 weeks following exposure. ${ }^{60}$

\section{Chronic effects of HCV infection}

As mentioned earlier, chronic infection by HCV causes slow progression of liver disease that leads to liver cirrhosis, CLD and hepatocellular carcinoma(HCC) over a period of 30 years ${ }^{61}$ Chronic liver hepatitis is the $5^{\text {th }}$ most common cause of death worldwide. ${ }^{62}$ The mean seroprevalence of $\mathrm{HCV}$ infection in the above mentioned diseases is shown in the following Table $4 .^{12}$

Table 4 Prevalence of HCV in patients with liver diseases

\begin{tabular}{ll}
\hline Type of the disease & $\begin{array}{l}\text { Mean seroprevalence of HCV } \\
\text { infection (\%) }\end{array}$ \\
\hline Liver cirrhosis & 44.9 \\
$\begin{array}{l}\text { Chronic liver disease (CLD) } \\
\text { Hepatocellular carcinoma } \\
\text { (HCC) }\end{array}$ & 52.9 \\
\hline
\end{tabular}

Above table shows the high prevalence of $\mathrm{HCV}$ in different hepatic (Liver) diseases. These diseases are the end stage of HCV infection and can lead to many complications which cause a great number of deaths in Pakistan. ${ }^{12}$ The mean age for developing CLD is lower in Pakistan than any other developed country, revealing that individuals are infected at an early age in this region of the world. ${ }^{63}$ Thus, if patients are provided proper preventive measures and timely diagnosis, they can be saved from such complications.

\section{Conclusion}

Reducing the incidence of $\mathrm{HCV}$ infection without preventive interventions, can be a major public health challenge. ${ }^{64}$ Therefore, more focus should be on primary prevention to control the disease burden of hepatitis C. ${ }^{65}$.

Majority of patients only discover that they are infected with HCV, when the disease expresses itself after a long period of time with all its complications. At that point of time, majority of the patients are beyond the scope of treatment and cannot even bear the expenses of treatment. Therefore, developing effective primary preventive measures is vital in order to prevent and control disease transmission.

\section{Conflicts of Interest \\ None. \\ Acknowledgements \\ None.}

\section{Funding}

None. 


\section{References}

1. Ali SA, Donahueb RM, Qureshi H, et al. Hepatitis B and hepatitis C in Pakistan: prevalence and risk factors. Int J Infect Dis. 2009;13(1):9-19.

2. Previsani N, Lavanchy D. Hepatitis B. World Health Organization WHO/CDS/CSR/LYO/2002.2, Geneva. 2002.

3. Hepatitis C. Geneva: World Health Organization; World Health Organization fact sheets. 2000.

4. Perz JF, Armstrong GL, Farrington LA, et al. The contributions of hepatitis $\mathrm{B}$ virus and hepatitis $\mathrm{C}$ virus infections to cirrhosis and primary liver cancer worldwide. J Hepatol. 2006;5(4):529-538.

5. National survey on Prevalence of Hepatitis B and C in Pakistan. Pakistan Medical Research Council, Pakistan. 2009.

6. Ghias M, Pervaiz MK. Identification of Epidemiological Risk Factors For Hepatitis C In Punjab, Pakistan. J Ayub Med Coll Abbottabad. 2009;21(2):156-161.

7. Pasha O, Luby SP, Khan AJ, et al. Household members of hepatitis C virus-infected people in Hafizabad, Pakistan: infection by injections from health care providers. Epidemiol Infect. 1999;123(3):515-518.

8. Bari A, Akhtar S, Rahbar MH, et al. Risk factors for hepatitis C virus infection in male adults in Rawalpindi-Islamabad, Pakistan. Trop Med Int Health. 2001;6(9):732-738.

9. Shah FU, Salih M, Malik IA, et al. Increasing prevalence of chronic hepatitis and associated risk factors. Pakistan JMed Res. 2002;41(2):4650 .

10. Rehman FU, Haq NU, Humayun M, et al. Risk of Hepatitis in Surgical Practice. J Postgrad Med Inst. 2002;16(2):157-160.

11. Akhtar S, Younus M, Adil S, et al. Hepatitis C virus infection in asymptomatic male volunteer blood donors in Karachi, Pakistan. Journal of Viral Hepatitis. 2004;11(6):527-535.

12. Umar M, Bushra H, Ahmad M, et al. Hepatitis C in Pakistan: a review of available data. Hepat Mon. 2010;10(3):205-214.

13. Sharara AI, Hunt CM, Hamilton JD. Hepatitis C. Annals of Internal Medicine. 1996;125:658-668.

14. World Health Organization Global surveillance and control of hepatitis C. J Viral Hepat. 1999;6(1):35-47.

15. World Health Statistics. World Health Organization, Geneva. 2008.

16. Chukwuemeka N. The threat of Hepatitis $\mathrm{C}-\mathrm{A}$ review of its implication for the developing Africa. Medikka Journal of the University of Nigeria Medical Students. 2006.

17. National Health Services Hepatitis C. 2009.

18. Cuthbert JA. Hepatitis C: Progress and Problems. Clin Microbi Rev. 1994;(4):505-532.

19. Beld M, Penning M, Putten M, et al. Low levels of Hepatitis C virus RNA in serum, plasma and peripheral Blood mononuclear cells of injecting drug users during long antibody- undetectable periods before seroconversion. Blood. 1999;94(4):1183-1191.

20. United Nations Development Program. Human Development Report. Oxford University Press, New York, USA. 1996

21. Wasley A, Alter MJ. Epidemiology of Hepatitis C: Geographic Differences and Temporal Trends. Semin Liver Dis. 2000;20(1):1-16.

22. Shepard CW, Finelli L, Alter MJ. Global epidemiology of hepatitis C virus infection. Lancet Infect Dis. 2005;5(9):558-567.

23. Khan AJ, Luby SP, Fikree F, et al. Unsafe injections and the transmission hepatitis $\mathrm{B}$ and $\mathrm{C}$ in a periurban community in Pakistan. Bulletin of the World Health Organization .2000;78(8):956-963.
24. Mirza S. Growing epidemic of hepatitis C: Lack of awareness among masses. Medpedia, San Francisco, USA. 2010.

25. Waheed Y, Shafi T, Safi SZ, et al. Hepatitis C virus in Pakistan A systematic review of prevalence, genotypes and risk factors. World $J$ Gastroenterol. 2009;15(45):5647-5653.

26. Hamid S, Tabbasum S, Jafri W. Hepatitis C has replaced Hepatitis B as the major cause of chronic liver disease in Pakistan. Hepatology. 2009;30(1):s212.

27. Chohan AR, Umar M, Khaar B, et al. Demographic features of hepatocellular carcinoma- A study of 30 cases. Journal of Rawalpindi Medical College. 2001;5:81-83.

28. Luby S, Khanani R, Zia M, et al. Evaluation of blood bank practices in Karachi, Pakistan, and the government's response. Journal of Pakistan Medical Association. 2006;56:S25-30.

29. Idress M, Lal A, Naseem M, Khalid M. High prevalence of hepatitis C virus infection in the largest province of Pakistan. Journal of Digestive Diseases. 2008;9(2):95-103.

30. Butt M. Health Care System in Pakistan. The Middle-East Journal of Family Medicine. 20006;4(3):49-50.

31. Janjua NZ, Akhtar S, Hutin YJ. Injection use in two districts of Pakistan: implications for disease prevention. Int $J$ Qual Health Care. 2005; 17(5):401-408.

32. Zafar A, Aslam N, Nasir N, et al. Knowledge, attitudes and practices of health care workers regarding needle stick injuries at a tertiary care hospital in Pakistan. J Pak Med Assoc. 2008;58(2):57-60.

33. Nishtar S. Corruption in the health sector in Pakistan. Heart file and transparency International 2007. 2007.

34. Jafri W, Jafri N, Yakoob J, et al. Hepatitis B and C: prevalence and risk factors associated with seropositivity among children in Karachi, Pakistan. BMC Infect Dis. 2006;6:101.

35. Karamat KA. Problem, Prevalence and Prevention of Viral Hepatitis in Pakistan; Health Planning Commission Pakistan. 2007.

36. Khan S, Rai MA, Khan A, et al. Prevalence of HCV and HIV infections in 2005-Earthquake-affected areas of Pakistan. BMC Infect Dis. $2008 ; 8: 147$.

37. Health Protection Agency. General Information on Hepatitis C. Health protection Agency, United Kingdom. 2010.

38. Franciscus A. HCV Transmission and Prevention-Hepatitis C Support Project. HCV Advocate. 2008.

39. Murphy EL, Bryzman SM, Glyn SA, et al. Risk Factors for Hepatitis C Virus Infection in United States Blood Donors. NHLBI Retrovirus Epidemiology Donor Study (REDS). Hepatology. 2000;31(3):756-762.

40. Ministry of Health. Annual report, Director General Health, 2001-2002; Government of Pakistan. 2000.

41. Siddiqi S, Hamid S, Rafique G, et al. Prescription practices of public and private health care providers in Attock District of Pakistan. Int J Health Plann Manage. 2002;17(1):23-40.

42. Kotwal A, Priya R, Thakur R, et al. Injection practices in a metropolis of North India: perceptions, determinants and issues of safety. Indian J Med Sci. 2004;58(8):334-344.

43. Luby SP, Qamruddin K, Shah AA, et al. The relationship between therapeutic injections and high prevalence of hepatitis $\mathrm{C}$ infection in Hafizabad, Pakistan. Epidemiol Infect. 1997;119(3):349-356.

44. Beltrami EM, Williams IT, Shapiro CN, et al. Risk and management of blood-borne infections in health care workers. Clin Microbiol Rev. 2000;13(3):385-407. 
45. Michalsen A, Delclos GL, Felknor SA, et al. Compliance with universal precautions among physicians. J Occup Environ Med. 1997;39(2):130137.

46. Henry K, Campbell S, Maki M. A comparison of observed and selfreported compliance with universal precautions among emergency department personnel at a Minnesota public teaching hospital: implications for assessing infection control programs. Ann Emerg Med. 1992;21(8):940-946.

47. Gershon RR, Vlahov D, Felknor SA, et al. Compliance with universal precautions among health care workers at three regional hospitals. Am J Infect Control. 1995;23(4):225-236.

48. Ramsey PW, McConnell P, Palmer BH, et al. Nurses' compliance with universal precautions before and after implementation of OSHA regulations. Clin Nurse Spec. 1996;10(5):234-239.

49. Nelsing S, Nielsen TL, Nielsen JO. Noncompliance with universal precautions and the associated risk of mucocutaneous blood exposure among Danish physicians. Infect Control Hosp Epidemiol. 1997;18(10):692-698.

50. Mele A, Corona R, Tosti ME, et al. Beauty treatments and risk of parenterally transmitted hepatitis: Results from the hepatitis surveillance system in Italy. Scand J Infect Dis. 1995;27(5):441-444.

51. Tummenelli F, Marcellini P, Rizzo S, et al. Shaving as potential source of hepatitis C virus infection (letter). Lancet. 1995;345(8950):658.

52. Koerner K, Cardoso M, Dengler T, et al. Estimated risk of transmission of hepatitis C virus by blood transfusion. Vox Sanguinis. 1998;74(4):213216.

53. Kuo G, Choo QL, Alter HJ, et al. An assay for circulating antibodies to a major etiologic virus of human non-A, non-B, hepatitis. Science. 1989;244(4902):362-364.

54. Sherlock S, Dooley J (eds). Diseases of the Liver and Biliary System. Blackwell Scientific Publications, Oxford, UK. 1993.

55. Anti-Narcotics Force. Drug abuse in Pakistan - results from year 2000 national assessment. Pakistan: United Nations Office for Drug Control and Crime Prevention and the Narcotics Control Division, Government of Pakistan, Pakistan. 2000.
56. United Nations Office for Drug Control and Crime Prevention. United Nations Office on AIDS: Baseline study of the relationship between injecting drug use, HIV and hepatitis $\mathrm{C}$ among male injecting drug users in Lahore. 1999.

57. Khan H, Khan N, Niazi R, et al. Seroprevalence of hepatitis C in Pakistanis visiting and admitted at the Pakistan Institute of Medical Sciences Islamabad. Journal of Surgery. 2001;1-22:22-26.

58. Shaikh F, Naqvi SQH, Jilani K, et al. Prevalence and risk factors for hepatitis C virus during pregnancy. Gomal Journal of Medical Sciences. 2009;7(2):86-88.

59. Alary M, Joly JR, Vincelette J, et al. Lack of evidence of sexual transmission of hepatitis $\mathrm{C}$ virus in a prospective cohort study of men who have sex with men. Am J Public Health. 2005;95(3):502-505.

60. U.S. Department of Veterans Affairs. Hepatitis C: For Health Care Providers .U.S. Department of Veterans Affairs, Washington, USA. 2010.

61. Shimotohno K. Hepatitis C virus and its pathogenesis. Semin Cancer Biol. 2000;10(3):233-240

62. Shaw-Stiffel TA. Chronic hepatitis. In: Mandell GL, Bennett JE, Dolin $\mathrm{R}$ et al. (Eds.) Principles and Practice of infectious diseases. ( $\left.5^{\text {th }} \mathrm{edn}\right)$, Churchill Livingstone, New York, USA. 2000:1297-1321.

63. Agboatwalla $\mathrm{M}$, Isomura $\mathrm{S}$, Miyake $\mathrm{K}$, et al. Hepatitis $\mathrm{A}, \mathrm{B}$ and $\mathrm{C}$ seroprevalence in Pakistan. Indian Journal of Pediatrics. 1994;61(5):545-549.

64. Inchauspe $\mathrm{G}$, Feinstone $\mathrm{S}$. Development of a hepatitis $\mathrm{C}$ virus vaccine. Clinics in Liver Disease. 2003;7(1):243-259.

65. Wright NM, Tompkins CN. A review of the evidence for the effectiveness of primary prevention interventions for Hepatitis $\mathrm{C}$ among injecting drug users. Harm Reduct J. 2006;3: 27. 